\title{
O PLANO DE DESENVOLVIMENTO DA ESCOLA (PDE ESCOLA) E A QUALIDADE DO ENSINO: DA SUA POLÍTICA DE IMPLEMENTAÇÃO, NO GOVERNO FHC (1998-2002), À SUA CONFIGURAÇÃO, NO GOVERNO LULA (2003-2010). ${ }^{1}$
}

\section{Crisolita Gonçalves dos SANTOS ${ }^{2}$ SEMEC/Igarapé-miri criksantos@hotmail.com}

Resumo: O presente artigo visa contextualizar como o Plano de Desenvolvimento da Escola (PDE Escola) se materializou nos governos FHC (1998-2002) e Lula (2003-2010), uma vez que passados mais de dez anos o PDE Escola continua presente na realidade da educação brasileira, ainda defendendo o discurso de melhoria na qualidade do ensino. O texto é um recorte da dissertação de mestrado intitulada "A gestão da política educacional em Igarapé-Miri e o PDE Escola: o lugar da autonomia e da qualidade do ensino". Esta é uma pesquisa qualitativa que utilizou a pesquisa de campo para sua efetivação. Tendo como principal enfoque de discussão o PDE Escola e seu foco na qualidade do ensino, o texto define a qualidade do ensino para além de uma proposta mensurável em educação, ultrapassando a concepção de que esta melhoria estaria somente relacionada a dados quantificáveis.

Palavras-chave: PDE Escola. Qualidade do ensino. FUNDESCOLA.

Abstract: This article aims to contextualize how the School Development Plan (PDE Escola) has materialized in the governments of FHC (1998-2002) and Lula (2003-2010), since after ten years, the PDE Escola remains defending the improvement speech in the quality of Brazilian education. The text is an excerpt of the dissertation entitled "The management of educational policy in Igarapé-Miri and the PDE Escola: the place of autonomy and quality of education." This is a

\footnotetext{
${ }^{1}$ Texto construído a partir da dissertação de mestrado intitulada "A gestão da política educacional em Igarapé-Miri e o PDE Escola: o lugar da autonomia e da qualidade do ensino" que foi defendida no Programa de Pós Graduação em Educação da UFPA, no dia 01 de junho de 2012.

${ }^{2}$ Licenciada Plena em Pedagogia- Campus Universitário do Baixo Tocantins/UFPA; Mestre em Educação. Linha Políticas Públicas em Educação. Programa de Pósgraduação da Universidade Federal do Pará/UFPA.
} 
qualitative study that used the field research for its enforcement. With the main focus on the discussion of PDE Escola and its focus on quality of teaching, the text defines the quality of education as a proposal which is beyond the measurable, surpassing the view that this improvement could be only related to quantifiable data.

Keywords: PDE Escola. education quality. FUNDESCOLA.

\section{Introdução}

O Plano de Desenvolvimento da Escola (PDE Escola), hoje configurado como uma das ações que compõem o Plano de Desenvolvimento da Educação (PDE), foi implementado em nosso país no final do século passado, por meio do FUNDESCOLA ${ }^{3}$ (Fundo de Fortalecimento da Escola), que se configurou como um Programa do Ministério da Educação (MEC), de responsabilidade direta do Fundo Nacional de Desenvolvimento da Educação (FNDE). O FUNDESCOLA foi proveniente de um acordo de financiamento firmado entre o MEC e o Banco Mundial (BM), com o objetivo de promover a realização de ações e projetos voltados para a formação continuada dos professores, para a implantação de metodologias de planejamento estratégico e de gestão educacional e para a adequação dos prédios escolares. Corroborando com tal perspectiva, França (2006, p. 155) destaca que:

o FUNDESCOLA foi criado com o objetivo de incentivar as reformas e melhorar a escola nos municípios [...] $O$ programa também prevê que, com a aplicabilidade dos recursos sendo feita diretamente pela unidade de ensino, se fortaleça a autonomia escolar.

Embora tenha sido um projeto implantado no âmbito da aplicação das propostas neoliberais em nosso país, o PDE Escola até hoje faz parte dos programas de governo implantados pelo MEC, assumindo a responsabilidade de transferir recursos diretamente para que a escola

${ }^{3}$ O Fundescola foi criado em junho de 1997, com recursos internacionais na ordem de 1,3 bilhão de dólares. Esse Programa, fruto de Acordo do Banco Mundial com o MEC, prioriza todo o ensino fundamental, sendo composto de 21 planos, programas e projetos (ver França, 2006). 
execute sua administração. No período de mais de uma década, algumas configurações foram alteradas. Hoje o PDE Escola está atrelado ao Índice de Desenvolvimento da Educação Básica (IDEB) e, a partir de 2007, passou a atuar na maioria das escolas brasileiras que ainda não haviam alcançado os níveis estimados para a educação no país. No entanto, compreendermos como essa configuração se faz presente, exige de nós um intenso repensar sobre as políticas educacionais implementadas nas últimas décadas do século passado e na primeira década do século atual, que foram principalmente demarcadas em dois governos que estiveram presentes na condução das políticas públicas, por oito anos cada um.

Nesse contexto, acreditamos ser de suma importância analisar, mesmo que de forma sucinta, as políticas educacionais dos governos Fernando Henrique Cardoso - FHC (1998- 2002) e de Luiz Inácio Lula da Silva - LULA (2003-2010), com o intento de compreendermos como o PDE Escola passa a ser, por meio do discurso do Ministério da Educação (MEC), um dos principais instrumentos de discussão da autonomia e da qualidade do ensino.

\section{A Política educacional do governo FHC (1998-2002): a implementação do PDE Escola}

Com a crise do capitalismo, vivenciada a partir do final do século $\mathrm{XX}$, novas formas de organização da política e da economia emergiam nas propostas governamentais, a fim de que uma nova lógica de mercado fosse edificada, sustentada mais na flexibilização das forças produtivas, sem, no entanto, deixar de lado a acumulação do capital e a dominação dos grandes centros econômicos.

Países como o Brasil, que desejavam subir os primeiros degraus de uma escala de desenvolvimento que envolvia um processo de industrialização e inserção no mercado de economia global, passaram então a reorganizar suas administrações públicas com o discurso de poder retirar o país da crise na qual se encontrava, principalmente devido ao esgotamento do Estado como provedor de serviços públicos.

Essa reorganização das administrações públicas afetou principalmente os setores sociais, e, no Brasil, foi intensamente defendida e efetivada por meio do Governo de Fernando Henrique Cardoso FHC 
(1995-2002) que, segundo as análises de Frigotto e Ciavata (2003, p. 103) foi um governo que:

conduziu as diferentes políticas de forma associada $e$ subordinada aos organismos internacionais, gestores da mundialização do capital e dentro da ortodoxia da cartilha do credo neoliberal, cujo núcleo central é a idéia do livre mercado e da irreversibilidade de suas leis.

A educação brasileira também foi afetada diretamente pelo processo de reformas do Estado e passou a ser orientada pelas determinações dos organismos internacionais, dentre eles o Fundo Monetário Internacional (FMI) e o Banco Mundial (BM), entre outros que possibilitaram que se efetivasse o que Frigotto e Ciavata (2003, p. 120) chamaram de "subordinação consentida aos organismos internacionais", principalmente atreladas ao Banco Mundial, por meio de empréstimos ao Ministério da Educação (MEC).

A lógica do mercado, então, ganha espaço consentido em nossa sociedade, pois esses financiamentos são conseguidos pautando-se nos discursos de melhorias para a qualidade do ensino e funcionamento das escolas, visto que com as dificuldades dos sistemas educacionais tornaram-se evidentes os altos índices de repetência e evasão, sem contar com o baixo nível de escolaridade da população. No entanto, essas reformulações da política educacional, alinhadas ao modelo neoliberal, contaram com a resistência de muitos profissionais e instituições educacionais que primavam pela formação de um cidadão mais autônomo e livre das amarras do mercado. Na luta travada entre a inserção da lógica mercadológica na política educacional, por meio do Governo FHC, e a defesa por uma educação que verdadeiramente assegurasse a formação integral dos cidadãos, configuravam-se também lutas constantes em torno da defesa de uma educação para a cidadania, na qual o educando deveria ser consciente de seu papel social e político.

Um dos grandes momentos registrados em torno desse debate se caracteriza pelas disputas para elaboração de uma nova Lei de Diretrizes para a Educação Nacional, que revelaria a nova posição da Política Educacional do país. Nesse embate, duas propostas para a Lei de Diretrizes e Bases da Educação brasileira tramitavam. Segundo Souza, 
Corrêa, Lofrano e Turqueti (2007, p. 26), esses projetos eram distintos "não apenas em estrutura, mas em intenções e atendimento de interesses, um na Câmara dos Deputados e outro no Senado Federal", sendo que aquele que tramitava na Câmara, mesmo passando por um processo de substituição e incorporação de várias emendas, representava o interesse da comunidade educacional, e o que tramitava no Senado estava articulado diretamente com o governo da época. No que diz respeito à aprovação da Lei $\mathrm{n}^{\circ}$ 9.394, de 20 de dezembro de 1996, Fernandes (2007, p. 74) enfatiza que "pelo fato de ter tido total apoio do MEC, tanto em sua elaboração como aprovação, reflete a política desenvolvida pelo atual governo no campo educacional".

Ao analisarmos a lei, observamos já em seu art. $2^{\circ}$ a filosofia que norteava os processos educacionais implantados por aquele período, ao destacar que:

a educação, dever da família e do Estado, inspirada nos princípios de liberdade e nos ideais de solidariedade humana, tem por finalidade o pleno desenvolvimento do educando, seu preparo para o exercício da cidadania e sua qualificação para o trabalho (Art. 2', LDB. 9.394/96).

Outro momento vivenciado, no final da década de 1990 e início do ano 2000, foi a elaboração do Plano Nacional de Educação:

Os planos nacionais de educação destinam-se a regulamentar a lei nacional de educação em termos de traduzir a política educacional em vigor em estratégias de cumprimento da lei. Esse procedimento supõe uma ampla negociação com a sociedade e com o Legislativo de modo que se garanta a orientação política da lei por meio da destinação efetiva de recursos e da elaboração de instrumentos legais complementares (FRIGOTTO e CIAVATA, 2003, p. 112).

No Brasil, desde a CF/88, é estabelecida a proposição de que seja elaborado um Plano Nacional para a educação brasileira, e isso é garantido através do Art. 214, onde se lê:

A lei estabelecerá o plano nacional de educação, de duração decenal, com o objetivo de articular o sistema nacional de 
educação em regime de colaboração e definir diretrizes, objetivos, metas e estratégias de implementação para assegurar a manutenção e desenvolvimento do ensino em seus diversos niveis, etapas e modalidades por meio de ações integradas dos poderes públicos das diferentes esferas federativas que conduzam a: I-Erradicação do analfabetismo; IIUniversalização do atendimento escolar; III- Melhoria da qualidade do ensino; IV- Formaşão para o trabalho; $V$ Promoção humanística, científica e tecnológica do País; VIEstabelecimento de meta de aplicação de recursos públicos em educação como proporção do produto interno bruto.

A elaboração do plano, no entanto, não ocorreu de forma pacífica e, mais uma vez, como aconteceu em decorrência da elaboração da LDB n ${ }^{\circ}$ 9.394/96, dois projetos tramitaram em nossas casas legislativas. Projetos marcados por posicionamentos divergentes quanto à concepção e finalidades da educação. Valente (2001, p. 11), ao discorrer sobre o processo de elaboração do Plano Nacional de Educação para vigência 2001-2011, expõe que:

A apresentação das duas proposições materializava mais do que a existência de dois projetos de escola, duas propostas opostas de politica educacional; elas de fato traduziam dois projetos antagônicos de país. Por um lado, o projeto democrático e popular, expresso na proposta da sociedade; por outro, o neoliberal - tradução da política do capital financeiro internacional e da ideologia disseminada pelas classes dominantes - devidamente refletido em termos de diretrizes e metas no projeto do governo.

E da mesma forma que aconteceu com a aprovação da LDB ${ }^{\circ}$ 9.394/96: a proposta do governo foi aprovada, deixando mais um momento importante da formulação da política educacional ser orientado por princípios neoliberais, que em nada pactuavam com uma atuação do Estado, com maior amplitude no oferecimento dos serviços essenciais aos cidadãos, como saúde, educação e segurança. Assim, passa a entrar em vigor a Lei $\mathrm{n}^{\mathrm{o}} 10.172$, de 09 de janeiro de 2001, que aprova o Plano Nacional de Educação para um período de 10 anos. Segundo Valente (2001), a lei retroage ao que havia sido disposto na $\mathrm{CF} / 88$, uma vez que houve 
uma redução na ênfase dos comandos, levando ao desaparecimento de objetivos amparados pela CF/88, como "a erradicação do analfabetismo". Tal omissão ou desaparecimento representa uma ruptura drástica com o objetivo da educação, uma vez que nosso país conta ainda com um número elevado de analfabetos.

Outro importante momento vivenciado no período de reformas educacionais na era FHC é o que faz referência à política de financiamento da educação. Segundo Gemaque (2006, p. 214), "a política de financiamento da educação de um governo expressa o grau de importância a ela atribuída" uma vez que ao definir o montante dos valores a serem implementados por meio dos programas, está aí evidenciada quais são as prioridades que serão assumidas, bem como os caminhos que deverão ser percorridos e as concepções que nortearão todo o processo.

Ao analisarmos a política de financiamento do Governo FHC, observamos que o grande feito aconteceu com a criação do FUNDEF (Fundo de Desenvolvimento e Manutenção do Ensino Fundamental) que "implantado nacionalmente passa a vigorar com a nova sistemática de redistribuição dos recursos destinados ao Ensino Fundamental" (FRANÇA, 2011, p. 357). Com o fundo, há uma priorização de $60 \%$ dos recursos destinados à educação para serem aplicados no desenvolvimento do ensino fundamental, com vistas a assegurar a universalização de seu atendimento e a remuneração aos profissionais do magistério.

Segundo França (2011), embora esse "Fundo contábil tenha representado um avanço no que diz respeito à valorização do educador dando-lhe condições para se habilitar [...] seu raio de abrangência ficou restrito tão somente ao ensino fundamental". Essa foi a principal crítica realizada em torno da criação do Fundo, uma vez que ajudou na exclusão de investimentos nos outros níveis de educação, como o ensino infantil, o ensino médio e a educação de jovens e adultos, além do fato de que a criação do Fundo possibilitou "a transferência de responsabilidades para estados e municípios e a indução da municipalização do ensino fundamental" (Ibid., p. 361).

Essas principais medidas acionadas no governo FHC explicitam claramente o que já vínhamos anteriormente ressaltando quanto ao seu compromisso com a implantação da política neoliberal em nosso país. Mas, Frigotto e Ciavata (2003, p. 108) nos alertam que: 
A dimensão talvez mais profunda e de consequiências mais graves situa-se no fato de que o Governo Fernando H. Cardoso, por intermédio do Ministério da Educação, adotou o pensamento pedagógico empresarial $e$ as diretrizes dos organismos e das agências internacionais $e$ regionais, dominantemente a serviço desse pensamento como diretriz e concepção educacional do Estado. Trata-se de uma perspectiva pedagógica individualista, dualista e fragmentária coerente com o ideário da desregulamentação, flexibilização e privatização e com o desmonte dos direitos sociais ordenados por uma perspectiva de compromisso social coletivo. Não é casual que a ideologia das competências e da empregabilidade esteja no centro dos parâmetros e das diretrizes educacionais e dos mecanismos de avaliação.

É o Estado defensor de uma concepção mercadológica aplicada aos processos educacionais, priorizando apenas o ensino fundamental. Essa proposição fica mais evidente quando analisamos a implantação, neste período, do FUNDESCOLA. Ele é originário de acordos internacionais firmados junto ao Banco Mundial e realizados em parceira com as secretarias municipais e estaduais de educação, que tinham como principal objetivo:

o desenvolvimento da gestão escolar, com vistas à melhoria da qualidade das escolas do ensino fundamental è permanência das crianças nas escolas públicas, nas regiōes Norte, Nordeste e Centro-Oeste (OLIVEIRA, FONSECA e TOSCHI, 2005, p. 128).

Os autores acima mencionados destacam ainda que:

O programa propõe-se a desenvolver ações de fortalecimento da escola ${ }^{4}$ por meio de convênios com os municípios, mediante adesão desses municípios. Para tanto, estados, municípios e escolas devem adotar a metodologia de planejamento estratégico, consubstanciada no modelo do PDE, que leve à racionalização, eficácia e eficiência da gestão e do trabalho escolar (Ibid. p. 03).

${ }^{4}$ Grifo do autor. 
O FUNDESCOLA, portanto, faz parte do processo de implantação de uma série de mecanismos na década de 1990, que instauraram uma nova lógica para os processos educacionais, nos quais a primazia se estabelecia em edificar uma educação adequada às exigências do mercado global, e, no Brasil, essa reforma, como dito anteriormente, foi mais intensificada no Governo FHC, o que nos possibilita concordar com Frigotto e Ciavata (2003, p. 122), quando destacam que "no campo educacional a era Cardoso foi de um retrocesso tanto organizativo como em termos pedagógicos", pois defendia uma educação totalmente desvinculada da perspectiva de formar um cidadão mais livre e verdadeiramente democrático.

Passada a "era Cardoso" vivenciamos uma nova era: a "era Lula". Luiz Inácio Lula da Silva governou o país de 2003 a 2010, também por um período de oito anos, e trouxe consigo a proposta de que novas posições seriam tomadas em relação à questão econômica, política e social, o que afetava diretamente a educação. Poder compreender como programas que foram implantados no âmbito do modelo neoliberal em nosso país permaneceram dentro de uma nova proposta de governo, que era proclamada com princípios totalmente diferenciados, é o que nos propomos fazer ao analisarmos a proposta de PDE Escola do Governo Lula.

\section{O governo Lula (2003-2010): uma nova configuração do PDE Escola?}

"A Educação foi destacada nos compromissos do governo federal 2003-2010 como um instrumento de promoção da cidadania, do desenvolvimento e da inserção competitiva do Brasil no mundo" (BRASIL, 2010, p. 7). É assim que se inicia o relatório Projeto Brasil $2003-$ 2010: Trajetórias e desafios - Evolução da Educação e da Saúde, que faz um balanço das ações do governo Lula nas áreas da Educação e da Saúde, tendo à frente da análise sobre a Educação Romualdo Portela de Oliveira, e, na análise sobre a Saúde, Carlos Augusto Grabois Gadelha. Esse documento foi lançado em 2010, sendo encontrado facilmente no site do MEC. Com o intuito de poder aprofundar a análise de como o Governo Lula gestou a educação nacional durante seus dois mandatos oficiais, reportaremo-nos à parte do documento que faz o balanço da educação nacional. 
No documento, são apresentados e avaliados os compromissos do governo federal no tocante à educação, no período citado, e a partir de seis tópicos claramente definidos em: 1- A formação da demanda por Educação; 2- Acesso à Educação Básica, compreendendo suas etapas e modalidades, e à Educação Superior, abrangendo tanto a graduação quanto a Pós-Graduação; 3- Qualidade da Educação Básica e Superior; 4Democratização da gestão educacional; 5- Financiamento da Educação; e, 6- Desafios na Educação. Inicialmente faremos uma breve exposição dos resultados do governo no relatório, e posteriormente traçaremos alguns comentários que julgamos pertinentes, a fim de que possam nos ajudar na compreensão de como as políticas do governo Lula possibilitaram uma redefinição, ou não, das políticas em educação no país, iniciadas a partir das reformas gerencialistas.

Uma simples e pontual leitura do documento possibilita-nos a compreensão de que no período destacado pelo documento, os aspectos considerados significativos em educação foram: a) a ampliação das oportunidades de escolarização da população e o aumento do índice de conclusão dos estudos, elevando à inclusão, nos períodos de estudos subsequentes; b) um significativo aumento nos níveis de alfabetizados da população com 15 anos ou mais; c) o estabelecimento do FUNDEB como reorganizador e possível equalizador na distribuição dos recursos para a educação básica; d) a implantação de um Piso Salarial Nacional para os professores; e) a tentativa de elevação dos recursos em educação. Entretanto, destacamos como indispensável nesse processo de leitura do documento que:

em seu conjunto, os dados sobre a Educação Básica indicam que ainda há muito a investir no atendimento em creche, na atratividade do Ensino Médio e, sobretudo na qualidade da formação oferecida" (BRASIL/MEC, 2012, p. 18).

Isso nos dá a certeza de que está evidente que precisamos continuar lutando para que melhorias sejam efetivadas como propostas efetivas e permanentes na educação.

O documento citado dá um forte destaque quando se refere ao PDE - Plano de Desenvolvimento da Educação -, que buscou redirecionar as 
relações no regime de colaboração entre a União e os Municípios, por meio da cooperação técnica e financeira. O PDE foi lançado em abril de 2007, e, segundo Saviani (2009, p. 5), esse plano:

aparece como um grande guarda-chuva que abriga praticamente todos os programas em desenvolvimento pelo MEC [...] trata-se, com efeito, de ações que cobrem todas as áreas de atuação do MEC, abrangendo os níveis $e$ modalidades de ensino, além de medidas de apoio $e$ financiamento.

Portanto, o PDE configura-se como um plano de organização das propostas que já vinham sendo implementadas, além de outras que passaram a ser inseridas no tocante à educação, tendo sempre o discurso da melhoria da qualidade do ensino como eixo principal de ação.

Partindo dessas referências, destacamos a observância que, embora a proposta do PDE seja considerada como um grande avanço, pois consiste numa forma de planejamento mais efetivo em torno da educação brasileira, acreditamos que não é só por meio de leis e decretos que iremos consolidar uma educação verdadeiramente de qualidade, e sim também propiciando maiores espaços de discussão, além de garantir melhorias na estrutura administrativa e na formação e execução do trabalho do professor.

O Plano de Desenvolvimento da Educação foi lançado simultaneamente com o Decreto ${ }^{\circ}$ 6.094, de 24 de abril de 2007, que institui o "Compromisso Todos pela Educação", que:

Dispõe sobre o Plano de Metas Compromisso de Todos pela Educação, pela União Federal, em regime de colaboração com Municípios, Distrito Federal e Estados, e a participação das famílias e da comunidade, mediante programas e ações de assistência técnica e financeira, visando à mobilização social pela melhoria da qualidade da educação básica (SAVIANI, 2009, p. 53).

No Plano de Metas "Compromisso Todos pela Educação" são estabelecidas 28 diretrizes desdobradas em ações que serão realizadas de forma "global e especifica" nos níveis de ensino e que incidiram

\section{9}


diretamente objetivando a melhoria da qualidade do ensino. Saviani (2009, p. 24), ao analisar o documento do MEC denominado O Plano de Desenvolvimento da Educação: razões, princípios e programas, que foi lançado em outubro de 2007, ressalta que:

ao definir como um dos eixos do Plano a "territorialidade",
elege o município como território privilegiado; e, no eixo da
"responsabilização", instituio PAR, visando responsabilizar
principalmente os gestores municipais pela qualidade do
ensino, assegurando-se apoio técnico e financeiro da União
com a eventual colaboração do estado em que se situa o
município signatário do convênio.

O PAR será o responsável em prestar o apoio técnico ou financeiro para que os municípios possam cumprir suas metas, via transferências voluntárias de recursos da União para os outros entes federados. Essa proposição foi considerada um avanço no estabelecimento de novas relações entre os entes federados. Assim, as ações de planejamento na esfera educacional são condicionadas ao PAR de cada município, que opta no encaminhamento de melhores alternativas para a condução da melhoria da qualidade do ensino, a partir do diagnóstico educacional elaborado por cada município estruturado em quatro grandes dimensões: Gestão Educacional; Formação de Professores e Profissionais de Serviço e Apoio Escolar; Práticas Pedagógicas e Avaliação; e Infraestrutura Física e Recursos Pedagógicos. Esse diagnóstico é realizado por uma equipe de trabalho denominada de equipe técnica local, que tem a responsabilidade de, além de construir o diagnóstico, elaborar o Plano de Ação do município. Será lá que estarão contidas todas as ações a serem desenvolvidas pelos municípios e que receberão apoio técnico e financeiro da união para implementação de sua proposta. No entanto, para que todos os programas e ações fossem executados, seria necessário que cada município assinasse voluntariamente o Compromisso Todos pela Educação. Embora tenha sido ressaltado que a adesão seria voluntária, o município que não aderisse ao Compromisso acabaria por ficar "fora" do estabelecimento desse novo formato de regime de cooperação, o que acabou por mobilizar todos os municípios para que assinassem o compromisso e elaborassem, posteriormente, seu PAR. 
Como envolvia a organização de um planejamento geral para a educação, o PDE (Plano de Desenvolvimento da Educação) assumiu a tarefa de abarcar todas as ações que vinham sendo implementadas, $\mathrm{e}$, nesse contexto, configura-se a continuação do desenvolvimento das ações do PDE Escola que, enfatizada por Saviani (2009), "é uma ação que se propõe a fortalecer a autonomia de gestão das escolas, envolvendo apoio técnico e financeiro às instituições de ensino para que elaborem seus próprios planos de gestão" (p. 09). A autonomia é ressaltada como condição indispensável ao processo de gestão da escola e à promoção da melhoria da qualidade do ensino.

Com a elaboração do PAR, os municípios passaram a ter mais acessibilidade a programas e ações do governo federal que muitas vezes ficavam distanciados das ações dos municípios. Assim, ações como o PDE Escola ganharam novas reconfigurações, passaram a estar mais próximas de municípios que solicitaram sua implantação como mecanismo de aplicação de insumos financeiros diretamente nas escolas para que estas, por meio de suas unidades executoras, pudessem viabilizar melhorias no processo educacional e na qualidade do ensino.

O PDE Escola passou a ser um grande mecanismo de distribuição de recursos financeiros para que as escolas que não tivessem alcançado os níveis estabelecidos pelo IDEB (Índice da Educação Básica) pudessem, baseadas num discurso de melhorias na qualidade do ensino, continuar seguindo as diretrizes iniciais por ocasião da implantação do PDE Escola, via FUNDESCOLA.

Mas a mudança real, percebida na gestão do PDE Escola, a partir do início do século XX, mais precisamente nos governos Lula, foi quando ele passou (em 2007) a compor o Plano de Desenvolvimento da Educação e seus Planos de Compromisso, pois passou a fazer parte de um sistema de gestão no qual o planejamento das ações estava mais em um planejamento global da educação.

No tocante à proposta em si, não foram realizadas mudanças na estrutura de elaboração do PDE Escola, o governo continuava a seguir o mesmo modelo de plano implementado anteriormente, mas ajudou a tornar o Plano mais próximo de muitas escolas, que acabaram por vivenciar processos de autonomia financeira no que diz respeito a construir um plano de ação para a escola que era financiável pelo governo federal. 
Vale ressaltar que tornar o plano mais próximo das escolas também propiciou que cada uma passasse a ser responsável diretamente em consolidar espaços educativos com mais qualidade, transferindo essa responsabilidade da esfera federal para uma esfera local. O PDE Escola também tem ajudado algumas escolas, principalmente as que conseguiram implementá-lo, com novas formas de gestão e planejamento do espaço escolar, pois evitou que muitas instituições de ensino apenas realizassem ações pontuais, sem, no entanto, realmente trabalhar com base em diagnósticos da realidade educacional.

O PDE Escola passou, nos últimos anos, a continuar referendando o discurso do MEC, afirmando que, por meio deste Projeto, a escola alcançaria melhores índices de qualidade no ensino, pois teria a oportunidade de, a partir da vivência diária, encontrar seus problemas e assim propor e viabilizar mecanismos para solucioná-los.

Observamos, portanto, que o Plano de Desenvolvimento da Educação com suas ações articuladoras (e aí está presente o PDE Escola) e com propósitos de melhoria na qualidade do ensino

representa um importante passo no enfrentamento do problema da qualidade da educação básica. Só o fato de pautar essa questão como meta da política educativa e construir instrumentos de intervenção já se configura como um dado positivo que precisa ser reconhecido. Mas, em sua configuração atual, ainda não nos dá grande êxito (SAVIANI, 2009 p. 41).

As afirmações de Saviani nos possibilitam a compreensão de que embora seja uma proposta que continua a fazer parte do conjunto de ações governamentais, enfatizando a qualidade do ensino, o PDE Escola ainda não alcançou grandes êxitos, pois:

com o PDE Escola ocorrem benefícios para a escola do ponto de vista físico e material, ele não tem contribuído para mudanças qualitativas no âmbito pedagógico, pois as matrizes que pautam suas estratégias esquecem que as escolas são espaços multifacetados de poder, de ideologias e perspectivas de sua própria função social (OLIVEIRA, 2006, p. 120). 
Assim, nossa compreensão da dimensão da qualidade de ensino para a educação brasileira ultrapassa a simples aplicação de um plano de trabalho que deve seguir exatamente as orientações de um manual que possui uma proposta gerencialista da educação. Não que estejamos desconsiderando todo o processo de construção da metodologia do plano, que por sinal acaba ajudando a escola na definição de novos rumos, apenas não concordamos com a execução de uma proposta que não possibilita verdadeiramente que a autonomia se estabeleça na instituição escolar. Acreditamos, todavia, que se faz necessário que compreendamos mais detalhadamente a proposta metodológica do PDE Escola, para assim evitarmos conclusões concisas a respeito dela. Esta é a proposta que desenvolveremos a seguir.

\section{Conclusão}

Passados 12 anos de sua implantação, e sendo materializado nas escolas brasileiras por meio de dois mandatos presidenciais, cada um com oito anos, e já completando quase dois anos de atuação no atual mandato, o PDE ainda faz parte do contexto escolar como proposta de descentralização de recursos financeiros federais, que passaram a ser administrados diretamente pela escola, com o intuito de melhorar a qualidade do ensino. Assim, é sempre importante destacarmos que o PDE Escola, como "produto" do FUNDESCOLA, é implementado como uma das principais matrizes da política de descentralização financeira a partir do contexto de inserção das políticas neoliberais em nosso país, nos anos 1990.

Não podemos deixar de destacar que tal proposição se firmava como a possibilidade de transferência da responsabilidade do Estado na promoção da melhoria da qualidade do ensino, o que nos levou à compreensão de que se descentralizavam as ações, mas centralizavamse as políticas elaboradas em nível federal. Assim, na verdade, o que acontecia era um processo de desconcentração.

O PDE Escola, então, estava para além de simplesmente investir em melhorias nos espaços educacionais, mas reforçava uma concepção de gestão gerencial para a educação, que aplicada aos moldes de gestão de empresas, passou a ver a escola também como uma empresa, sendo capaz 
de produzir melhores serviços por meio da racionalização do trabalho, do emprego da metodologia do planejamento estratégico e do uso racional dos recursos. Sendo essa a concepção de qualidade da educação pensada para os modelos educacionais, resulta em uma qualidade mais centrada em resultados quantificáveis do que uma qualidade verdadeiramente social para a educação.

\section{REFERÊNCIAS}

BRASIL. Constituição Federal de 1988. $2^{\text {a }}$ ed. São Paulo: Oliveira Mendes, 1998.

Lei Federal no 9394, de 20 de dezembro de 1996. Estabelece as Diretrizes e Bases da Educação Nacional. Diário Oficial da União, de 23 de dezembro de 1996.

. MEC, Banco Mundial, FUNDESCOLA. Boletim Técnico $\mathrm{n}^{\circ}$. 62, ano VII, Brasília 2002.

. MEC Banco Mundial, FUNDESCOLA. Boletim Técnico $n^{\circ}$. 61, ano VII, Brasília 2002.

. MEC Banco Mundial, FUNDESCOLA. Boletim Técnico $\mathrm{n}^{\circ}$. 57, ano VII, Brasília 2002.

MEC. Banco Mundial. FUNDESCOLA. Boletim Técnico. $\mathrm{n}^{\circ} .56$, ano VII, Brasília, 2002.

MEC. Relatório Projeto Brasil 2003-2010: Trajetórias e desafios - Evolução da Educação e da Saúde. Coordenação Romualdo Portela de Oliveira e Carlos Augusto Grabois Gadelha. Brasília 2010. Disponível em: < www.mec.gov.br > Acesso em: 03/01/2011.

Sinopse das Ações do MEC. Edição 1/2011. Série Cadernos de Gestão. Disponível em: < www.mec.gov.br> Acesso em: 03/01/2011. FERNANDES, Ângela Viana Machado. O contexto e o texto da Lei de Diretrizes e Bases da Educação de 1996: 10 anos atrás. In: RESCIA, Ana Paula O; SOUZA, Cláudio Benedito Gomide de; GENTILINI, João A; RIBEIRO, Ricardo (Org.). Dez anos de LDB: contribuições para a 
discussão das políticas públicas em educação no Brasil. 1 ed. Araraquara: UNESP, 2007.

FRANÇA, Magna. A descentralização financeira e o Fundescola: o Plano de Desenvolvimento da Escola, Programa de Adequação dos Prédios Escolares e sua expansão no Rio Grande do Norte In: NETO Antonio Cabral (Org.). Política Educacional no Brasil: compartilhando saberes e reflexões. Porto Alegre: Sulina, 2006.

Qualidade da educação: recursos da união, o FUNDEB e o PNE (2011-2020) In: FRANÇA, Magna; SOUSA - JUNIOR, Luiz de; FARIAS, Maria da Salete Barboza de (Org.). Políticas de gestão e práticas educativas: a qualidade do ensino. Brasília: Líber Livro, 2011.

FRIGOTO, Gaudêncio. Educação e crise do capitalismo real. 5 ed. São Paulo: Cortez 2003.

CIAVATTA Maria. Educação Básica no Brasil na década de 1990: subordinação ativa e consentida à lógica do mercado. Rev. Educ. Soc., Campinas, abril 2003, v. 24, n. 82, p. 93-130. Disponível em: < $\underline{\text { http:// }}$ www.cedes.unicamp.br $>$.

GEMAQUE, Rosana Maria Oliveira. Financiamento da Educação no Governo Lula e as metas do Plano Nacional de Educação. In: GEMAQUE, Rosana Maria Oliveira; LIMA, Rosangela Novaes. Políticas Públicas Educacionais: O Governo LULA em questão. Belém: CEJUP, 2006.

OLVEIRA, Ney Cristina M. de. A gestão educacional e o currículo: projetos em tensão em nome da qualidade do ensino. In: GEMAQUE, Rosana Maria Oliveira; LIMA, Rosangela Novaes (Org.). Políticas Públicas Educacionais - O Governo Lula em questão. Belém: CEJUP, 2006.

SANTOS, Terezinha Fátima A. Monteiro dos. Conversas impenitentes sobre a gestão da educação. Belém: EDUFPA, 2008.

SAVIANI, Demerval.PDE-Planode Desenvolvimentoda Educação: Análise crítica da política do MEC. Campinas: Autores Associados, 2009.

SOUZA, Cláudio Benedito Gomide de; CORRÊA, Luis Fabiano Corrêa; LOFRANO, Ruth Corrêa; TURQUETI, Adriana da Silva. A normatização da educação no Brasil e a nova LDB. In: RESCIA, Ana 
Paula O.; SOUZA, Cláudio Benedito Gomide de; GENTILINI, João A; RIBEIRO, Ricardo (Org.). Dez anos de LDB: contribuições para a discussão das políticas públicas em educação no Brasil. 1 ed. Araraquara: UNESP, 2007.

VALENTE, Ivan. Plano Nacional de Educação. Rio de Janeiro: DP\&A Editora, 2001.

VASCONCELOS, Helena C.; OLIVEIRA, Ilda Estela A.; SANTOS, Terezinha Fátima Andrade Monteiro (elaboradoras). Plano de Desenvolvimento da Escola - PDE. Relatório da Pesquisa Avaliativa realizada em Belém. Belém: [s.n], 1999.

VIEIRA, Soraya. Resenha de: FONSECA, Marília; TOSCHI, Mirza Seabra; OLIVEIRA, João Ferreira de. (Org.). Escolas gerenciadas: planos de desenvolvimento e projetos político-pedagógicos em debate. Goiânia: Editora da UCG, 2004. 